\title{
Human Intersexuality: Difference or Disorder?
}

\author{
Milton Diamond
}

Published online: 28 October 2008

(C) Springer Science+Business Media, LLC 2008

In January 2008, I had been invited to the University of Hamburg to speak on the management of intersex conditions as I saw the current situation. While there, I was unexpectedly given an award by the German Intersex Society (Intersexuelle Menschen e.V.). As part of the award presentation, the group specifically complimented me for disputing the renaming of intersex with the acronym DSD with its meaning of Disorders of Sex Development. This intersex support group praised first encouraging the use of VSD for Variations of Sex Development (Tamar-Mattis \& Diamond, 2007) and then DSD with the meaning of Differences of Sex Development (Diamond \& Beh, 2008). The latter two acronyms removed the stigma accompanying the use of the word Disorder as part of an identifying characteristic while the latter transformation of DSD maintained the original convenience of the DSD abbreviation.

DSD meaning Disorder, while developed by a consortium of clinicians and others (Hughes, Houk, Ahmed, Lee, \& LWPES/ESPE Consensus Group, 2006), was not derived at by any official organization but by a self-selected group. The terminology and meaning given to DSD has been strongly spoken against by the largest international organization of intersexed persons as being demeaning and insulting (http:// www.intersexualite.org/Response_to_Intersex_Initiative. html).

For those that argue that the use of Disorder as a description of the conditions referred to is a benefit to those that can gain from having a "medical condition" covered by insurance there are other instances where conditions exist that do not have to be labeled as a disorder to benefit from insurance coverage and they occur without being stigmatic and demeaning. The prime example is pregnancy. Personally, I have not encountered any parent or adult that was pleased with being informed they or their child had a disorder. I have met many that accept that there are differences.

The designation DSD can certainly be maintained but with the meaning of Differences of Sex Development. Doing so would not be a loss to the original intent of removing previous stigmas using terms such as hermaphrodite or pseudohermaphrodite but would be an enhancement and improvement to the original intent. It would be an improvement in the treatment of those with intersex conditions.

\section{References}

Diamond, M., \& Beh, H. G. (2008). Changes in management of children with differences of sex development. Nature Clinical Practice Endocrinology \& Metabolism, 4, 4-5.

Hughes, I. A., Houk, C., Ahmed, S. F., Lee, P. A., \& LWPES/ESPE Consensus Group. (2006). Consensus statement on management of intersex disorders. Archives of Disease in Childhood, 91, 554-563.

Tamar-Mattis, A., \& Diamond, M. (2007). Managing variations in sex development. Journal of Pediatric Endocrinology and Metabolism, 20, 552-553.
M. Diamond ( $\square)$

Pacific Center for Sex and Society, John A. Burns School of Medicine, University of Hawaii, 1960 East-West Road, Honolulu, HI 96822, USA

e-mail:diamond@hawaii.edu 